\title{
General practitioner prescribing habits in asthma/COPD
}

K Peperell, M Rudolf, M Pearson and J Diggle

\begin{tabular}{|c|c|}
\hline \multicolumn{2}{|l|}{ ABSTRACT } \\
\hline Objective: & $\begin{array}{l}\text { To evaluate the economic implications } \\
\text { of prescribing for asthma/COPD. }\end{array}$ \\
\hline Design: & $\begin{array}{l}\text { Analysis of computerised prescribing } \\
\text { records over a six month period. }\end{array}$ \\
\hline Setting: & Nine general practices in the UK. \\
\hline Subjects: & $\begin{array}{l}\text { Two hundred and twenty seven patients } \\
\text { diagnosed as 'asthma', } 193 \text { patients } \\
\text { diagnosed as 'COPD', all of whom } \\
\text { were most likely to have COPD. }\end{array}$ \\
\hline Results: & $\begin{array}{l}\text { Prescribing costs were } £ 51,920 \text {. Inhaled } \\
\text { corticosteroids had been prescribed for } \\
81 \% \text { of patients; reducing this to } 20 \% \\
\text { would generate savings of } £ 21,834 \text {. }\end{array}$ \\
\hline Conclusion: & $\begin{array}{l}\text { The use of COPD guidelines in general } \\
\text { practice may release savings to improve } \\
\text { accuracy of diagnosis, treatment and } \\
\text { clinical outcomes. }\end{array}$ \\
\hline
\end{tabular}

INTRODUCTION

Chronic obstructive pulmonary disease (COPD) is a major cause of morbidity and mortality in the UK, especially in the elderly., It has been estimated that 5-8\% of men and almost as many women have COPD, with cigarette smoking being the most important risk factor. ${ }^{3}$

Audit studies suggest that a third of patients over the age of 40 attending asthma clinics may have COPD, even Whilst corticosteroids are of great benefit in asthma, their role in COPD has yet to be established. European, UK and US guidelines agree that regular long-term inhaled steroid therapy should only be given if there is clear evidence of objective response. ${ }^{5-7}$

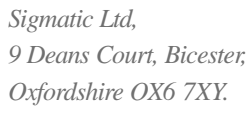

Michael Rudolf Consultant Respiratory Physician

Ealing Hospital,

Middlesex UB1 $3 \mathrm{HW}$.

Michael Pearson

Consultant Physician

Aintree Chest Centre,

Liverpool L9 7AL

John Diggle

General Practitioner

ISCA General Practice Unit, Gwent NP6 1AZ

Correspondence to: Kate Peperell

Asthma in Gen Pract 1997; 5(2): 29-30.

Optimal therapy of COPD is with bronchodilators which is usually less expensive than long-term treatment with inhaled steroids. Correct diagnosis and management of COPD will result in savings which can be directed towards improving the treatment accuracy and the appropriateness of treatment.

The aims are to document the prescribing habits of GPs in these areas and assess the extent to which COPD may have been misdiagnosed as asthma and to explore the economic implications of more accurate diagnosis and implementation of guidelines

\section{METHODS AND PATIENTS}

The study was carried out in nine UK general practices (Table 1). Potential subjects for the study were identified

Table 1: Details of participating practices

\begin{tabular}{lrc|}
$\begin{array}{l}\text { Practice } \\
\text { location }\end{array}$ & $\begin{array}{c}\text { Approximate } \\
\text { list size }\end{array}$ & $\begin{array}{c}\text { No. of patients } \\
\text { contributed to study }\end{array}$ \\
\hline Norwich & 4,500 & 48 \\
Essex & 14,500 & 18 \\
Essex & 7,400 & 26 \\
Essex & 7,750 & 40 \\
Stockport & 3,172 & 47 \\
Brierley Hill & 6,900 & 53 \\
Leeds & 11,500 & 66 \\
Cardiff & 8,600 & 67 \\
Stirling & 4,472 & 69
\end{tabular}
though their diagnosis and management is for asthma. ${ }^{4}$

by carrying out a search of the practices' computerised prescribing records to select patients who were (i) over the age of 40 , (ii) prescribed a $\beta_{2}$-agonist within a defined six month period, and (iii) had a history of smoking. By reviewing the medical notes of these patients only those who also had (iv) predicted PEF persistently less than $70 \%$, (v) chronic sputum production, and (vi) a history of chest infections were then included in the study.

For each patient satisfying these six criteria, the diagnosis was noted, together with full details of all $\beta_{2}$-agonist, anticholinergic and corticosteroid prescriptions during the preceding six months. Each prescription was individually costed (noting whether it was for a generic or branded product), with the following assumptions:

i) For inhaled drugs, it was assumed that one device was issued on each prescription.

ii) Where the dosage of an inhaled drug was specified but not the unit strength of the device, the cost was calculated using the most common formulation.

iii) For nebulised drugs, it was assumed that each prescription was for one standard pack of nebules/ respules/unit dose vials.

Only a small number of patients were prescribed prednisolone, these trivial costs were not included.

\section{Results}

The total number of patients entered into the study was 434, 210 (48\%) were male and 224 (52\%) female. Mean age was 65 years (range 40-91). The diagnosis was recorded as asthma in 227 (52\%) and COPD (including chronic bronchitis and/or emphysema) in 193 (45\%); 14 (3\%) had either neither, or another, diagnosis.
The total cost of all drugs prescribed in the six month period was $£ 51,920$. The separate costs are shown in Table 2, together with a breakdown into different formulations. Table 3 shows the percentages of patients prescribed each main category of drug, together with the average cost per patient, calculated for the number of patients who were actually prescribed each drug.

\section{DISCUSSION}

The accurate differentiation between asthma (with reversible airflow obstruction) and COPD (with chronic slowly progressive airflow obstruction) requires both bronchodilator reversibility testing and long-term measurements of spirometry. In clinical practice, COPD is likely in the presence of chronic progressive symptoms, a history of smoking, and objective evidence of lung function that does not respond to treatment.

Although the six entry criteria in this study were specifically chosen to identify subjects who probably did have COPD rather than asthma, $52 \%$ of the patients had a recorded diagnosis of asthma. In addition to any economic implications of treating COPD as if it were asthma, this finding raises questions about the validity of PACT data in auditing asthma care in general practice. The ratio of inhaled steroid: bronchodilator is often quoted as an indicator of the quality of prescribing for asthma, with a 
higher ratio being regarded as good practice. ${ }^{8}$ The failure of a recent study to correlate admission rates for asthma with FHSA steroid: bronchodilator PACT data may partly have been due to the presence of patients with COPD confounding the association that was being investigated. ${ }^{9}$

The overall drug costs of $£ 51,920$ equate to an average annual cost of $£ 239$ per patient. The majority of spending in each of the drug categories was on metered dose inhalers, with the single exception of anticholinergics where a higher proportion of the cost was due to the prescribing of nebulised therapy (Table 2).

Over half of the total prescribing costs were due to inhaled corticosteroids. Guidelines for the management of COPD point out that the role of long-term inhaled steroids has yet to be fully established, and that they should only be used if there is clearly demonstrated functional benefit after a course of prednisolone; this only occurs in $10-30 \%$ of patients. ${ }^{5-7}$ In this study, $81 \%$ of the patients were receiving steroids at an average cost of $£ 82.65$ per patient for six months, (Table 3 ) and a total cost of $£ 29,008$. If only $20 \%$ of patients were to receive inhaled steroids, the cost would be reduced to $£ 7,174$, a saving of $£ 21,834$.

A number of studies are currently investigating the longterm effects of inhaled steroids on decline of lung function in patients with COPD. Substantial savings could still be made even if a higher proportion of patients are shown to benefit from corticosteroids (Figure 1)

In a recent review of the hospital drug charts of 1,500 inpatients aged over 60 , of 183 patients receiving both $\beta_{2}-$ agonists and corticosteroids, in only $51 \%$ was the steroid therapy judged to be appropriate. It was more likely to be inappropriate in the more elderly patients. ${ }^{10}$

Division of prescribing costs into those patients with a recorded diagnosis of asthma and those with a recorded diagnosis of COPD allows for some other interesting deductions. If the recorded diagnosis of asthma was regarded as correct by the GPs, it is disappointing that, though all patients had persistently low lung function, only $81 \%$ of the 'asthmatic' patients had been prescribed inhaled steroids. On the other hand, even if the diagnosis of COPD was actually correct only in those 193 patients where this diagnosis had been recorded, significant savings can still be identified. If, for example, only $20 \%$ of this group received steroids rather than the $72 \%$ who actually did, at an average cost of $£ 97.96$ per patient, then a saving of $£ 9,831$ could still be achieved.

Although the vast majority of patients were receiving $\beta_{2}-$ agonists, only $23 \%$ of patients were prescribed an anticholinergic and $12 \%$ a combination formulation of an anticholinergic plus a $\beta_{2}$-agonist. The percentages in those patients labelled as having COPD were slightly higher ( $31 \%$ and $14 \%$ respectively). Yet all COPD treatment guidelines state that anticholinergics are at least as efficacious as $\mathrm{B}_{2}$-agonists in COPD, and prescribing both may be even more effective. This low usage of anticholinergic therapy in COPD is possibly due to both under-recognition of the disease and poor understanding of its optimal bronchodilator treatment.

\section{CONCLUSIONS}

The results of this study have demonstrated that there are major economic implications associated with the correct

Table 2: Costs of prescriptions over six month period for all 434 patients

\begin{tabular}{|c|c|c|c|c|c|}
\hline Drug & $\begin{array}{l}\text { Metered dose } \\
\text { inhalers }\end{array}$ & $\begin{array}{l}\text { Dry powder } \\
\text { devices }\end{array}$ & $\begin{array}{c}\text { Nebulised } \\
\text { preparations }\end{array}$ & Tablets & Total \\
\hline $\begin{array}{l}\beta_{2} \text {-agonist } \\
\text { Anticholineraic }\end{array}$ & $£ 10,022$ & $£ 3,376$ & $£ 2,496$ & $£ 835$ & $£ 16,729$ \\
\hline $\begin{array}{l}\beta_{2} \text {-agonist/ } \\
\text { anticholinergic } \\
\text { combination }\end{array}$ & $\begin{array}{l}£ 1,583 \\
£ 1,141\end{array}$ & & $\begin{array}{r}£ 2,553 \\
£ 746\end{array}$ & - & $\begin{array}{l}24,295 \\
£ 1,887\end{array}$ \\
\hline Corticosteroid & $£ 19,424$ & $£ 6,385$ & $£ 3,200$ & - & $£ 29,008$ \\
\hline
\end{tabular}

Table 3: Percentages of patients prescribed different drugs, with average costs per patient

\begin{tabular}{lccc} 
& $\begin{array}{c}\text { All patients } \\
(\mathbf{n}=\mathbf{4 3 4})\end{array}$ & $\begin{array}{c}\text { Patients diagnosed } \\
\text { with asthma }(\mathbf{n}=\mathbf{2 2 7})\end{array}$ & $\begin{array}{c}\text { Patients diagnosed } \\
\text { with COPD }(\mathbf{n = 1 9 3})\end{array}$ \\
\hline$\beta_{2}$-agonist & $91 \% £ 42.03$ & $87 \% £ 43.50$ & $88 \% £ 46.22$ \\
Anticholinergic & $23 \% £ 43.40$ & $13 \% £ 38.67$ & $31 \% £ 52.83$ \\
$\beta_{2}$-agonist/ & $12 \% £ 35.61$ & $11 \% £ 25.62$ & $14 \% £ 47.13$ \\
$\begin{array}{c}\text { anticholinergic } \\
\text { combination }\end{array}$ & $81 \% £ 82.65$ & $81 \% £ 81.41$ & $72 \% £ 97.96$ \\
$\begin{array}{c}\text { Inhaled } \\
\text { corticosteroids }\end{array}$ & & &
\end{tabular}

diagnosis and management of asthma and COPD in general practice. The implementation of COPD guidelines, in particular those relating to the prescribing of inhaled steroids, could generate savings that might then be reinvested in the practice.

\section{Acknowledgements} We are grateful to the GPs for the use of their prescribing data, and to Boehringer Ingelheim Ltd for financial support

\section{References}

1. Lung \& Asthma Information Agency. The burden of respiratory disease. 1995; Fact sheet 95/3.

2. Lung \& Asthma Information Agency. The geography of COPD mortality in the elderly. 1996; Factsheet 96/1.

3. Pride N B. Epidemiology, aetiology and natural history of chronic obstructive pulmonary disease. In: Brewis R A S, Corrin B, Geddes D M and Gibson G J, (eds). Respiratory Medicine, 2nd edition, W.B. Saunders Co. Ltd. 1995; 1021-33.

4. Diggle J. Asthma audit uncovers COPD. General Practitioner, June 9th 1995.

5. British Thoracic Society. Guidelines for the management of chronic obstructive pulmonary disease. Thorax 1997; in press.

6. European Respiratory Society. Optimal assessment and

management of chronic obstructive pulmonary disease. Eur Respir

J 1995; 8: 1398-420

7. American Thoracic Society. Standards for the diagnosis and care of patients with chronic obstructive pulmonary disease. Am J Respir Crit Care Med 1995; 152: S77-S120.

8. Audit Commission. A prescription for improvement: towards more rational prescribing in general practice. London HMSO 1994; 26-7

9. Shelley M, Croft P, Chapman S et al. Is the ratio of inhaled corticosteroid to bronchodilator a good indicator of the quality of asthma prescribing? Cross sectional study linking prescribing data to data on admissions. BMJ 1996; 313: 1124-6.

10. Oborne A. Steroids in obstructive airways disease.

Pharmaceutical Journal 1996; 257: 838 